\title{
Panoramic Radiographic Assessment of Status of Impacted Mandibular Third Molars: A Tertiary Care Centre Based Study in Eastern Nepal
}

\author{
Pragya Regmee, ${ }^{1}$ Jyotsna Rimal, ${ }^{1}$ Iccha Kumar Maharjan, ${ }^{1}$ Surya Raj Niraula ${ }^{2}$ \\ ${ }^{1}$ Department of Oral Medicine and Radiology, ${ }^{2}$ School of Public Health and Community Medicine, B. P. Koirala \\ Institute of Health Sciences, Dharan, Nepal.
}

\section{ABSTRACT}

Background: Mandibular third molar (M3M) is the most posterior of the three molars present in each quadrant. Racial variation, genetic inheritance etc can affect the jaw size, size of tooth and ultimately the eruption state of M3M. So, studies of impacted M3Ms have been carried out in various populations. But data relating to these are not evident from most of the parts of Nepal. Hence, this study was done to assess the status of impacted M3Ms in a tertiary care center in eastern Nepal. Materials \& Methods: Total of 220 patients' M3Ms (i.e 440 sites of M3Ms) were assessed with Panoramic Radiographs, in Department of Oral Medicine and Radiology. The impaction status was divided as class of impaction (I, II, III), level of eruption (A, B, C) and angulation (mesioangular, vertical, distoangular and horizontal). Data were entered in Microsoft excel sheet and analyzed using SPSS software version 11.5. Results: Class II impaction state was most commonly present in this population group, in 345 sites $(85.18 \%)$ while none of the patients had class III impaction. Level A eruption was most prevalent, 315 sites $(77.78 \%)$. The least prevalent was level C eruption, 14 sites (3.46\%). Majority 18 sites $(46.67 \%)$ had vertical inclination while only 32 sites (7.9\%) had horizontal inclination. Conclusion: The most prevalent impaction state of M3M in this population group is Class II, Level A with vertical angulation.

Keywords: impacted teeth; mandible; panoramic radiography; third molar.

\section{INTRODUCTION}

Mandibular third molar (M3M) is the most posterior of the three molars present in each quadrant. M3M cannot always erupt into its position because of various factors like lack of space, genetic factors and anthropometric causes. This state of third molar or any other teeth, is called impaction of a tooth. ${ }^{1}$

Classifications play a key role in completing the evaluation of $\mathrm{M} 3 \mathrm{M}$ position and assessment of procedural challenges which further help in planning optimal surgical technique to allow easy removal with minimal morbidity, thus, avoiding any serious or permanent complications. Several classifications have been known and proposed but Winter and Pell \& Gregory are most commonly used clinically. ${ }^{2}$

Studies have shown that impacted third molar weakens the angle of mandible, making it susceptible to fracture either during removal or due to trauma. The position of any mandibular third molar is categorized radio-graphically according to the antero-posterior space between the second molar and the anterior border of mandibular ramus, its superior-inferior position and the position of its long axis. ${ }^{3}$ This classification is universally accepted, easy to coordinate between dentists and even in record maintaining and treatment planning. Of the third molars present in the study done by Sandhu and Kaur, ${ }^{1} 31 \%$ were in mesioangular position and $42 \%$ were in vertical position. Out of 354 teeth examined, $24 \%$ of teeth were found to be erupted and $76 \%$ were in various stages of eruption. Similar results were seen in various other studies.

These kinds of studies thus help in classifying mandibular third molars into various stages of eruption, different angulations and different forms of impaction. Racial variation, nature of diet, degree of use of masticatory apparatus, and genetic inheritance can affect the jaw size and tooth size. Studies of prevalence and incidence of impacted M3Ms have been carried out on different population groups by

Correspondence: Dr. Pragya Regmee, Department of Oral Medicine and Radiology, College of Dental Surgery (CODS),BPKIHS, Dharan, Nepal. Email: mailpragyareg@gmail.com. DOI: 10.3126/jcmsn.v14i2.20187. Orcid ID: http://orcid.org/0000-0001-6982-8496. Article received: 2018-06-07. Article accepted: 2018-06-21. 
various authors. ${ }^{1}$ The direct application of the various parameters; like angulation of third molar, level of eruption and class of eruption; will be during the extraction procedures of third molar. ${ }^{4}$ Thus, the aim of the present study was to determine the status of impacted M3Ms, among a population of patients visiting the Department of Oral Medicine and Radiology, College Of Dental Surgery (CODS), B. P. Koirala Institute of Health Sciences (BPKIHS), Dharan, Nepal. This was done on the basis of panoramic radiographic presentation.

\section{MATERIALS AND METHODS}

This study was conducted after the approval from Institutional Review Committee of BPKIHS. This was a prospective hospital based study, done on patients indicated for Panoramic Radiograph. It was conducted in the Department of Oral Medicine And Radiology, College of Dental Surgery, BPKIHS. The duration of study was one year (September, 2015 to September, 2016) and the total sample size was 220 (total of 440 sites bilaterally). Convenient sampling technique was used for sample collection.

According to findings of right and left sides, total number of patients was divided into asymptomatic group, symptomatic group, and radiographic group, on each side of mandible.

Group I: Side with clinically visible and asymptomatic M3M (Asymptomatic group)

Group II: Side with clinically visible and symptomatic M3M (Symptomatic group)

Group III: Side with clinically no evidence of $\mathrm{M} 3 \mathrm{M}$, which was radiographed for some other condition (Radiographic group)

Patients who were above 17 years old and who were willing to give consent were included in the study.

Following groups of patients were excluded:

1. Any patient with history of extraction of permanent tooth.

2. Any patient with mandibular fracture, or orthodontic treatment.

Patients with developmental anomaly of face, congenital or systemic disease and/or major pathology in the mandible that has/had caused severe bone resorption/destruction, ankylosis, facial asymmetry, bone expansion, root resorption and tooth migration.

3. Patients with multiple impacted or multiple supernumerary teeth.

4. Third molars having underdeveloped roots.

5. Patients with grossly decayed M3M where mesodistal dimension of crown could not be assessed.

6. Patients not willing to give consent

Information sheet was provided to all the participants of the study. Informed consent was obtained, history was taken and patients were examined clinically under aseptic condition. Radiographs were taken by Panoramic Machine (Gendex Orthoralix 9200 DDE, Cusano Milanino, Italy), which has a constant magnification of 1.25. Image were produced by digital imaging technique and the recordings were made by using ImageJ software. ${ }^{5}$ Calibration of the images were done by placing a one $\mathrm{cm}$ long lead foil block over the patient's bridge of the nose, during the time of image acquisition. A predesigned proforma was filled for each patient volunteering in the study. Confidentiality and privacy of the patients were maintained.

Following Ganss Method ${ }^{6}$, occlusal plane was drawn through the tip of the most superior cusps of the first premolar and the most superior mesial cusps of second molar, extending up to anterior border of the ramus. A perpendicular line was drawn from the occlusal plane touching the most distal point of the second molar (Figure 1).

The available third molar space was determined as the distance between the intersection of the occlusal plane with the anterior border of the ramus and the intersection of the perpendicular line on the occlusal plane through the distal most point of the second molar above the alveolar bone. The mesiodistal width of the third molar crown was also recorded.

The class of M3M impaction was recorded as follows: $:^{7,8}$

Class I: Adequate room for eruption of a third molar if eruption could occur (Available space will be more or equal to mesiodistal diameter of third

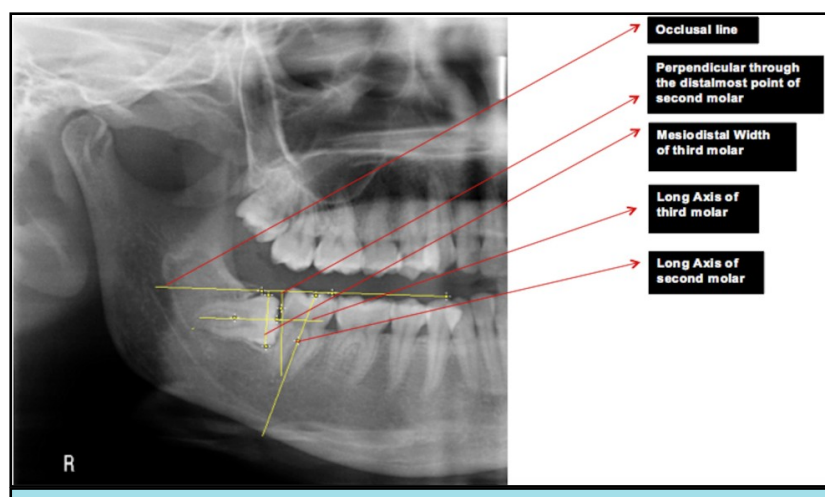

Figure 1. Measurements done using ImageJ software. 
molar)

Class II: Partial space posterior to the second molar and the ascending ramus of the mandible (Available space will be less than mesiodistal diameter of third molar)

Class III: If the tooth will be located completely within the mandibular ramus.

Level of eruption was recorded as: ${ }^{1,9}$

Level A: The highest point of the crown of third molar at or above the occlusal line

Level B: The highest point below the occlusal line and at or above the cervical line

Level C: The highest point of the crown below the cervical line

The inclination of third molars was determined by measuring the angle formed between the line intersecting the long axis of the second and third molars, drawn through the midpoint of the occlusal surface and bifurcation. ${ }^{1}$

Vertical: If angle is $+/-10$ degree

Mesioangular: If angle is +11 degree to +70 degree

Distoangular: If angle is -11 degree to -70 degree

Horizontal: If angle is more than $+/-70$ degree

"+ sign" denotes that intersection of line was above the molars and "- sign" denotes that intersection of line was below the molars.

Single investigator had done all the measurements and Kappa agreement for different variables ranged from good (0.954) to perfect (1).

For class of impaction: 0.954 (good).

For level of eruption, angulation: 1 (perfect).

The data collected was entered in Microsoft Excel Sheet. It was then transferred to SPSS (Statistical Package for Social Sciences, version 11.5). Chi square test was used for categorical data and $\mathrm{p}$ value of $<0.05$ was considered significant.

\section{RESULT}

A total of 220 patients, that is, 440 sites of M3Ms (bilaterally) were evaluated. The mean $\pm \mathrm{SD}$ age of participants was $(29.20 \pm 11.24)$ years. Total numbers of female participants were $120(54.54 \%)$ and $100(45.45 \%)$ were male.

Out of the total 440 sites of M3Ms examined, 21 patients had agenesis of M3M on the right side while 14 patients had agenesis of M3M on the left side. Thus, the total number of M3Ms assessed in this study was 405 (199 on the right side and 206 on the left side)

There were 189 sites of M3Ms in asymptomatic group and 135 sites of M3Ms in symptomatic group. Symptoms in these patients varied from caries, discomfort to pain or difficulty in mouth opening or swelling. There were a total of 81 sites of $\mathrm{M} 3 \mathrm{Ms}$ in radiographic group.

Table 1 shows the different classes of eruption of $\mathrm{M} 3 \mathrm{M}$ on the right side while Table 2 shows the distribution of classes of eruption on the left side. Both of the sides showed maximum number of patients in class II impaction state (161 sites $(80.9 \%)$ on right side and 184 sites $(89.32 \%)$ on the left side) while none of the patients had class III impaction.

\begin{tabular}{|cccccc|}
\hline \multicolumn{5}{|l|}{ Table 1. Different Classes of Impaction of } \\
M3M on the right side (n=199). & & \\
\hline $\begin{array}{l}\text { Class of } \\
\text { Impaction }\end{array}$ & $\begin{array}{c}\text { Group } \\
\text { I }\end{array}$ & $\begin{array}{c}\text { Groupt side } \\
\text { Group }\end{array}$ & $\begin{array}{c}\text { Group } \\
\text { III }\end{array}$ & Total & $\begin{array}{c}\text { P- } \\
\text { value }\end{array}$ \\
& 26 & 8 & 4 & 38 & \\
I & 59 & 63 & 39 & 161 & \\
II & 0 & 0 & 0 & 0 & NA \\
III & 85 & 71 & 43 & 199 & \\
Total & NA: Not Applicable (chi square test/ fisher's exact test) \\
\hline
\end{tabular}

\begin{tabular}{|c|c|c|c|c|c|}
\hline \multirow{2}{*}{$\begin{array}{l}\text { Class of } \\
\text { Impaction }\end{array}$} & \multicolumn{3}{|c|}{ Left side } & \multirow[b]{2}{*}{ Total } & \multirow{3}{*}{$\begin{array}{c}\text { P- } \\
\text { value }\end{array}$} \\
\hline & Group I & $\begin{array}{c}\text { Group } \\
\text { II }\end{array}$ & $\begin{array}{c}\text { Group } \\
\text { III }\end{array}$ & & \\
\hline I & 17 & 5 & 0 & 22 & \\
\hline II & 87 & 59 & 38 & 184 & \multirow{3}{*}{ NA } \\
\hline III & 0 & 0 & 0 & 0 & \\
\hline Total & 104 & 64 & 38 & 206 & \\
\hline NA: No & Applicable & chi squ & test/ fis & r's exc & est) \\
\hline
\end{tabular}

The clustered column in Figure 2 and 3 shows the class of impaction in female and male on the right and left sides respectively. In both the sides and both the gender, maximum number of participants had class II impaction state.

Table 3 tabulates the different level of eruptions (A, $\mathrm{B}$ and $\mathrm{C}$ ), which was seen on the right side. 159

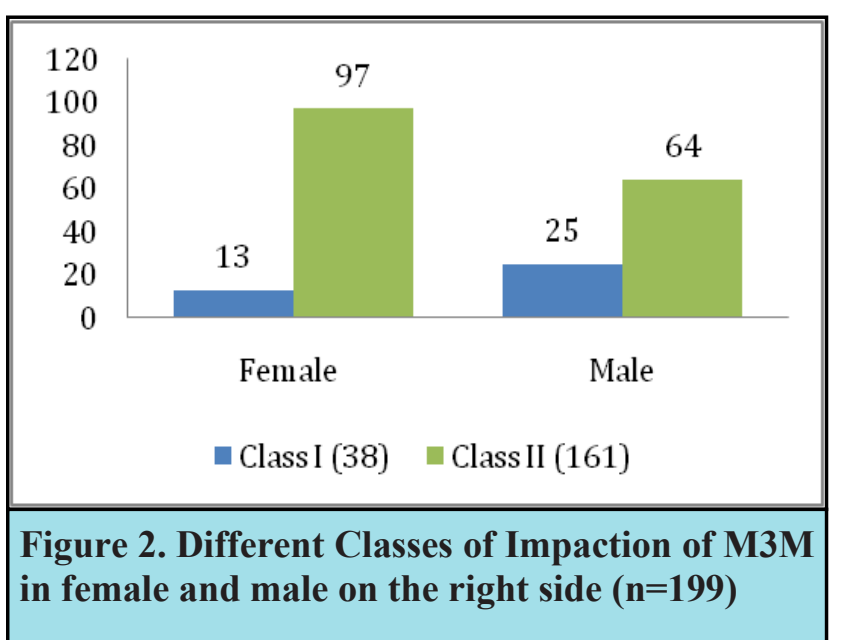


Regmee et al. Panoramic Radiographic Assessment of Status of Impacted Mandibular Third..

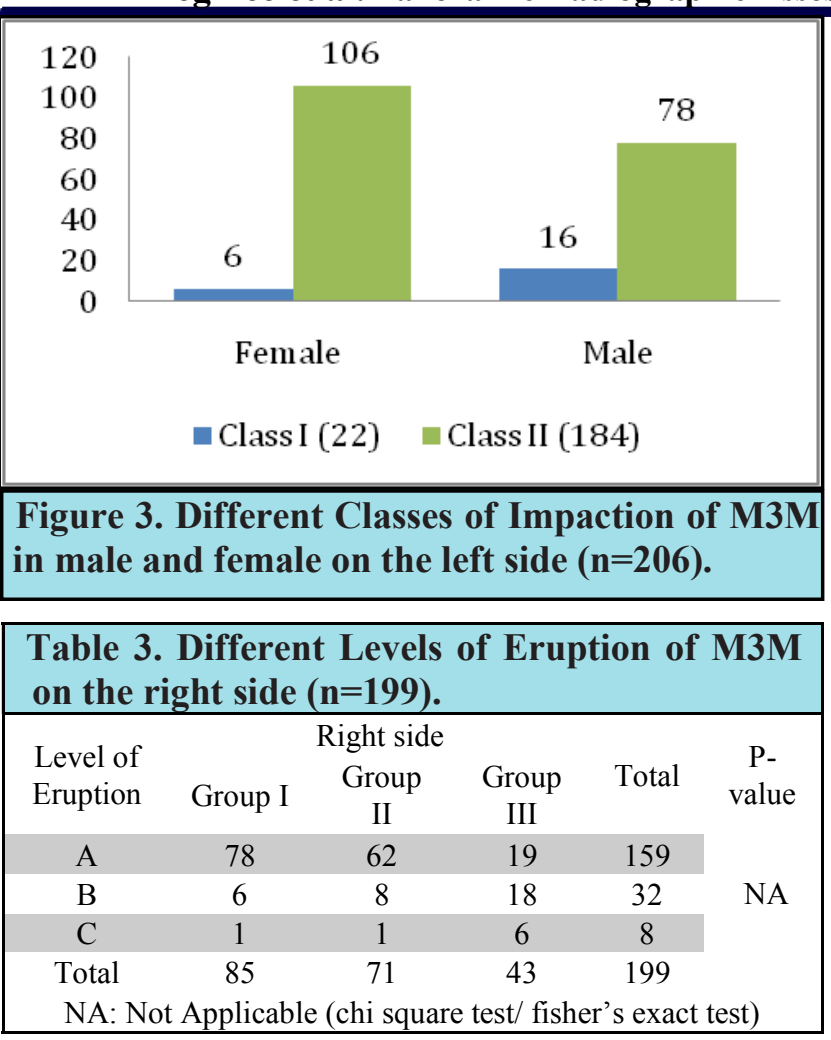

participants (79.89\%) had level A eruption, 32 $(16.08 \%)$ had level B and eight participants $(4.02 \%)$ had level $\mathrm{C}$ eruption.

Likewise on the left side, 156 participants $(75.73 \%)$ had level A eruption, $44(21.36 \%)$ had level B eruption and remaining six (2.91\%) participants had level $\mathrm{C}$ eruption (Table 4).

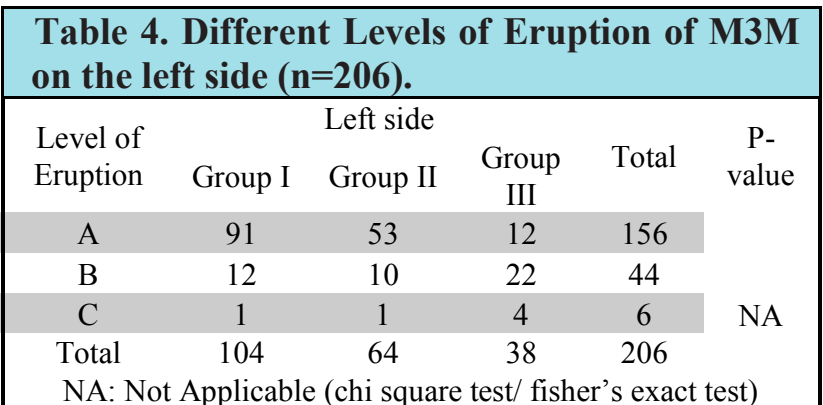

The clustered column in Figure 4 and 5 shows the level of eruption in female and male on the right and left sides respectively. In both the sides and both the gender, maximum number of participants had eruption till level A.

In determining the angulation of $\mathrm{M} 3 \mathrm{M}$ on the right side, majority i.e. 90 sites $(45.22 \%)$ had vertical inclination while only 14 sites $(7.03 \%)$ had horizontal inclination (Table 5).

Similar kind of tabulation summarizing the findings

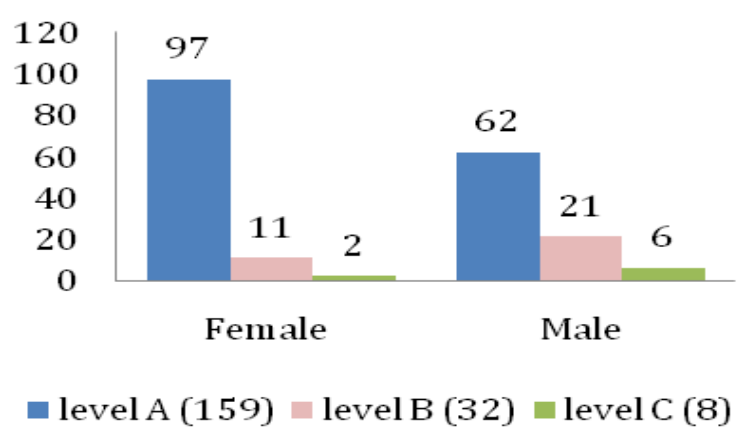

Figure 4. Different Levels of eruption of M3M in female and male on the right side $(n=199)$.

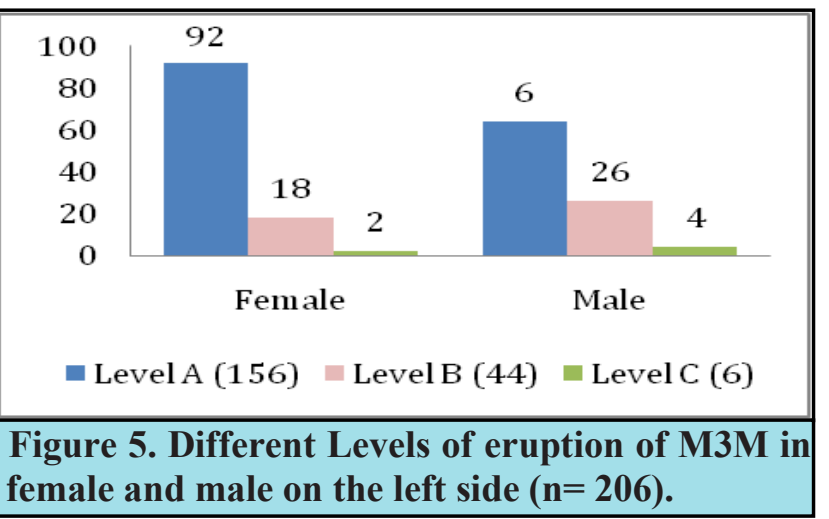

on the left side, shows that 99 (48.05\%) patients had vertical inclination while only 18 (8.74\%) patients had horizontal inclination (Table 6).

Clustered bar in Figure 6 and 7 depicts the prevalence of different angulations in male and

\begin{tabular}{|c|c|c|c|c|c|}
\hline \multicolumn{5}{|c|}{ Right side } & \multirow{3}{*}{$\begin{array}{c}\mathrm{P}- \\
\text { value }\end{array}$} \\
\hline Angulation & $\begin{array}{c}\text { Group } \\
\text { I }\end{array}$ & $\begin{array}{c}\text { Group } \\
\text { II }\end{array}$ & $\begin{array}{c}\text { Group } \\
\text { III }\end{array}$ & Total & \\
\hline Mesioangular & 20 & 14 & 31 & 65 & \\
\hline Horizontal & 2 & 6 & 6 & 14 & \multirow{4}{*}{ NA } \\
\hline Vertical & 51 & 36 & 3 & 90 & \\
\hline Distoangular & 12 & 15 & 3 & 30 & \\
\hline Total & 85 & 71 & 43 & 199 & \\
\hline
\end{tabular}

\begin{tabular}{|c|c|c|c|c|c|}
\hline & & Left side & & & $\mathrm{P}-$ \\
\hline Angulation & $\begin{array}{c}\text { Group } \\
\text { I }\end{array}$ & $\begin{array}{l}\text { Group } \\
\text { II }\end{array}$ & $\begin{array}{c}\text { Group } \\
\text { III }\end{array}$ & Total & $\begin{array}{c}\text { valu } \\
\mathrm{e}\end{array}$ \\
\hline Mesioangular & 23 & 18 & 22 & 63 & \multirow{5}{*}{ NA } \\
\hline Horizontal & 5 & 5 & 8 & 18 & \\
\hline Vertical & 61 & 33 & 5 & 99 & \\
\hline Distoangular & 15 & 8 & 3 & 26 & \\
\hline Total & 104 & 64 & 38 & 206 & \\
\hline NA: Not Ap & cable (c) & square & fishe & exac & \\
\hline
\end{tabular}


Regmee et al. Panoramic Radiographic Assessment of Status of Impacted Mandibular Third..
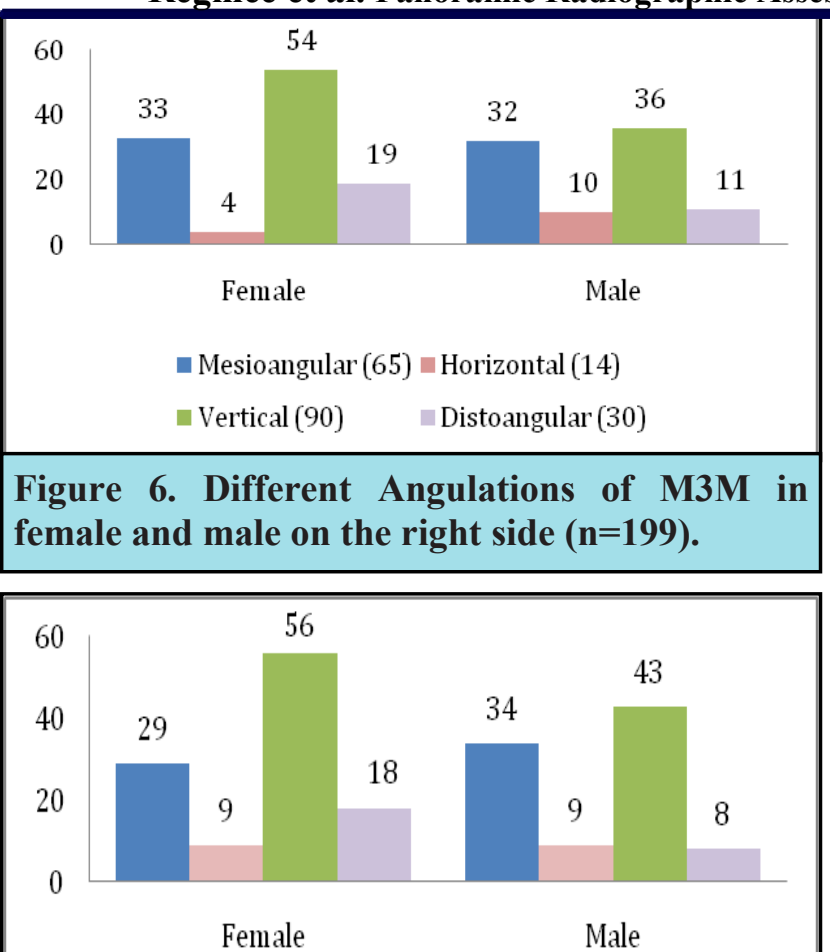

$$
\begin{aligned}
& \text { " Mesioangular (63) ఐ Horizontal(18) } \\
& \text { - Vertical (99) Distoangular(26) }
\end{aligned}
$$

Figure 7. Different Angulations of M3M in female and male on the left side $(n=206)$.

female on the right and left side respectively. Here as well, vertical angulation was seen in majority of the patients and the least prevalent among all the angulations was horizontal on both the sides.

No significant difference between the class of impaction, level of eruption and angulation was found when right and left sides were compared. Also, no statistically significant difference between the class of impaction, level of eruption and angulation was found when compared between male and female.

\section{DISCUSSION}

Mandibular third molar impaction has become a frequent dental discovery over a period of last few decades affecting that proportion of population, which engages the normal eruption age range of third molars. This finding remains unveiled until patient undergoes radiographic investigations for supplementary dental ailment or when any symptom/complication associated with third molar becomes apparent. Numerous studies have been conducted from across the globe to find the prevalence of pattern of mandibular third molar angulation and position (both in vertical and horizontal plane). ${ }^{10}$
This study included the study population from age group 17 and above because the eruption age for third molars starts at the age of $17 .^{11}$

The current study has shown that majority of our patients were asymptomatic, bilaterally, during their presentation in the clinic. Though statistical tests could not be applied, we can imply that in this population group though the $\mathrm{M} 3 \mathrm{M}$ is impacted there is less chance for them to present with a symptom.

The result of this study showed that among the various classes of impaction, Class II was most prevalent; this finding is supported by many other studies conducted in other population groups. The least prevalent impaction state is Class III in these studies; however, none of the patients in our study showed Class III impaction state. ${ }^{12-14}$

In the study conducted by Gupta et al., ${ }^{12}$ majority of the participants $(61.84 \%)$ had level A eruption followed by level B (32.48\%) and level C eruption $(5.66 \%)$. The findings in the present study are similar to the findings in the above-mentioned study.

Also, there are many literatures which show that the maximum prevalence is that of level A eruption and the least is that of level $\mathrm{C}$ eruption. ${ }^{2,13,15,16} \mathrm{In}$ addition, there are few studies, which have found that level B eruption was the most prevalent. $1,17,18,14$

Inconsistent to these findings, the study by Topkara and $\operatorname{Sari}^{18}$ found that level A eruption was the least prevalent among the impacted M3Ms and the study by Jung and Cho ${ }^{19}$ showed that level $\mathrm{C}$ was the most prevalent in patients aged over 40 .

The present study shows that maximum prevalence was that of vertical angulation and minimum was that of horizontal angulation in both the sides and both the gender. Few studies have got similar findings. ${ }^{12,17}$ On the other hand, many studies have found that the most prevalent angulation is mesioangular. ${ }^{1-3,20-23}$ Similarly, the systematic review by Carter and Worthington ${ }^{24}$ also concluded that the most prevalent angulation is mesioangular and the least prevalent is horizontal. A study by Jung and Cho ${ }^{19}$ had findings inconsistent to these. In the study, the most prevalent angulation was horizontal while the least was distoangular.

The present study reveals no significant difference 
in the class of impaction, level of eruption and angulation between the right and left sides. Similar finding was seen in a study by Gupta et al. ${ }^{12}$ This implies that there is a strong chance that a patient has same class of impaction, level of eruption and angulation of M3M bilaterally in mandible. Also, no significant difference was found in the class of impaction, level of eruption and angulation when compared between male and female. This implies that, in this population group, both male and female has similar impaction state.

In this study, angulation of M3M did not differ significantly among males and females on both the sides but in the study conducted by Topkara and Sari, ${ }^{18}$ Al-Anqudiet al. ${ }^{15}$ and Rahman et al., ${ }^{23}$ significant difference was found in angulation between male and female.

These different studies have different findings, which can be attributed to differences in sample

\section{REFERENCES}

1. Sandhu S, Kaur T. Radiographic evaluation of the status of third molars in the Asian-Indian students. J Oral Maxillofac Surg 2005;63(5):640-5.DOI: 10.1016/j.joms.2004.12.014

2. Kaur P. Prevalence of mandibular third molar impaction pattern in a private dental clinic of Sultanpur Lodhi. Int J Heal 2015;3(2):4752.DOI: 10.14419/ijh.v3i2.5173

3. Punjabi SK, Khoso NA, Butt AM, Channar KA. Third molar impaction: Evaluation of the symptoms and pattern of impaction of Mandibular third molar teeth. J Liaquat Univ Med Heal Sci 2013;12 (1):26-9.

4. LJ P. Contemporary Oral and Maxillofacial Surgery. 3rd ed. Ellis E III, Hupp JR TM, editor. St. Louis: Mosby; 1998. 215-48 p.

5. Kerner S, Etienne D, Malet J, Mora F, MonnetCorti V, Bouchard P. Root coverage assessment: validity and reproducibility of an image analysis system. J Clin Periodontol 2007;34(11):96976.DOI:10.1111/j.1600-051X.2007.01137.x

6. Lucchese A, Manuelli M. Prognosis of third molar eruption: a comparison of three predictive methods. Prog Orthod 2003;4(2):4-19.

7. Hattab FN, Alhaija ES. Radiographic evaluation of mandibular third molar eruption space. Oral Surg Oral Med Oral Pathol Oral Radiol Endod 1999;88 (3):285-91.

8. Chiapasco M, De Cicco L, Marrone G. Side effects and complications associated with third molar surgery. Oral Surg Oral Med Oral Pathol 1993;76 (4):412-20.

9. Marciani RD. Third Molar Removal: An Overview of Indications, Imaging, Evaluation, and Assessment of Risk. Oral Maxillofac Surg Clin North Am 2007;19(1):1-13.DOI:10.1016/j.coms.2006.11.007 sizes, statistical methods, and diagnostic criteria besides the racial, topographic and anthropometric differences.

Regarding the limitations of this study, the major concern with this study is the lack of random sampling, which was avoided to avoid unnecessary radiographic exposure to the patients. But, it may have created sampling bias. Also, because of the expected cell count being less than five in many of the tables statistical tests could not be applied. If the tests could have been applied, we could have generated more useful information. This could have been avoided if the sample size was increased.

As a further recommendation, we would like to suggest studies with larger sample size in different parts of the country. This will generate national database of the status of impacted M3M in whole of the country.

10. Alamgir W, Mumtaz M, Kazmi F, Baig MA. Cause and Effect Relationship Between Mandibular Third Molar Impactions and Associated Pathologies. 2015;3(1):762-7.

11. Juodzbalys G, Daugela P. Mandibular third molar impaction: review of literature and a proposal of a classification. J oral Maxillofac Re 2013;4 (2):e1. DOI: 10.5037/jomr.2013.4201

12. Gupta S, Bhowate RR, Nigam N, Saxena S. Evaluation of impacted mandibular third molars by panoramic radiography. ISRN Dent 2011;2011:406-14. DOI: $10.5402 / 2011 / 406714$

13. Obiechina AE, Arotiba JT, Fasola AO. Third molar impaction: evaluation of the symptoms and pattern of impaction of mandibular third molar teeth in $\mathrm{Ni}$ gerians. Odontostomatol Trop 2001;24(93):22-5.

14. Eshghpour M, Nezadi A, Moradi A, Mahvelati Shamsabadi R, Rezaei NM, Nejat A. Pattern of mandibular third molar impaction: A cross-sectional study in northeast of Iran. Niger J Clin Pract 2014;17 (6):673-7. DOI: 10.4103/1119-3077.144376

15. Al-Anqudi SM, Al-Sudairy S, Al-Hosni A, AlManiri A. Prevalence and Pattern of Third Molar Impaction: A retrospective study of radiographs in Oman. Sultan Qaboos Univ Med J 2014;14(3):e38892.

16. Byahatti S, Ingafou MSH. Prevalence of eruption status of third molars in Libyan students. Dent Res J 2012;9(2):152-7.DOI: 10.4103/1735-3327.95228

17. Costa FWG, Fontenele EHL, Bezerra TP, Ribeiro TR, Carneiro BGDS, Soares ECS. Correlation between radiographic signs of third molar proximity with inferior alveolar nerve and postoperative occurrence of neurosensory disorders: a prospective, double-blind study. Acta Cir Bras 2013;28(3):221-7.

18. Topkara A, Sari Z. Investigation of third molar impaction in Turkish orthodontic patients: Prevalence, 


\section{Regmee et al. Panoramic Radiographic Assessment of Status of Impacted Mandibular Third..}

depth and angular positions. Eur J Dent 2013;7 (Suppl 1):S94-8.DOI: 10.4103/1305-7456.119084

19. Jung Y-H, Cho B-H. Prevalence of missing and impacted third molars in adults aged 25 years and above. Imaging Sci Dent 2013;43(4):219-25. DOI: 10.5624/isd.2013.43.4.219

20. Celikoglu M, Miloglu O, Kazanci F. Frequency of Agenesis, Impaction, Angulation, and Related Pathologic Changes of Third Molar Teeth in Orthodontic Patients. J Oral Maxillofac Surg 2010;68 (5):990-5.DOI: 10.1016/j.joms.2009.07.063

21. Saad SS, Saffar AB Al, Minwah BS. Relation of the Mandibular Canal to the Root Apices of Different Types of Impacted. Al-Rafidain Dent J. 2012;12 (1):109-14

22. Syed KB, Zaheer KB, Ibrahim M, Bagi MA, Assiri
MA. Prevalence of Impacted Molar Teeth among Saudi Population in Asir Region, Saudi Arabia - A Retrospective Study of 3 Years. J Int oral Heal 2013;5(1):43-7.

23. Rahman SA, Alam MK, Woei KC. Pattern of Angulations of Mandibular Third Molar Impaction in a Malaysian Population: A Retrospective Radiographic Investigation Pattern of Angulations of Mandibular Third Molar Impaction in a Malaysian Population: A Retrospective Radiographic. Int Med J. 2014;21:120-2.

24. Carter K, Worthington S. Predictors of Third Molar Impaction: A Systematic Review and Metaanalysis. J Dent Res 2015;95(3):267-76. DOI: $10.1177 / 0022034515615857$

Citation: Regmee P, Rimal J, Maharjan IK, Niraula SR. Radiographic assessment of status of impacted mandibular third molars: A tertiary care centre based study in eastern Nepal. JCMS Nepal. 2018;14(2):85-91. 